\title{
Needs assessment study of genetics education for general practitioners in Australia
}

\author{
Sylvia Metcalfe, $P h D^{1}$, Rosalind Hurworth, $P h D^{2}$, Jennifer Newstead, $M B B S^{3}$, and Rosemary Robins, $P h D^{4}$
}

\begin{abstract}
Purpose: Because of the explosion of genetic information resulting from the Human Genome Project and other developments in genetics and genetic technologies, primary care practitioners in Australia will be expected to have a much greater role in the practice of genetic medicine; however, little is published regarding their knowledge and attitudes to genetics, technologies, or genetics education. This study aimed to determine the genetics knowledge and educational needs of general practitioners (GPs) in Victoria, Australia, and their experiences in dealing with genetics in their practices. Methods: Qualitative research methods were used primarily to obtain data from focus groups, interviews, and a limited survey. Results: GPs believed their knowledge of genetics was poor and they felt inadequately prepared to manage patients with genetic conditions. They identified testing and counseling as areas that particularly needed strengthening. Conclusion: These data, together with GPs' suggestions about educational strategies, are essential for developing appropriate genetics education programs and resources that are relevant for Australian health care. Genet Med 2002:4(2):71-77.
\end{abstract}

Key Words: genetics education, general practitioners, attitudes, educational strategies, primary care

The explosion of genetic information resulting from the Human Genome Project (HGP) and other developments in genetics and genetic technologies is expected to have major implications for doctors in primary care. ${ }^{1-4}$ Francis Collins, who directed the public effort of the HPG, has stated that "virtually every disease has a genetic component, except possibly trauma," 4 and it is becoming increasingly apparent that, to a greater or lesser extent, genetics underpins much of medicine, including health promotion and disease prevention and treatment. $^{2}$

Although it is acknowledged that the full impact from the HGP will not be faced immediately in clinical practice, concerns regarding provision of genetic services in several countries in the northern hemisphere have been raised..$^{5-7}$ Correspondingly, in Australia, the impact on genetic services is being felt, and recommendations for greater provision of services in Victoria have been made in a Working Party report. ${ }^{8}$

The overriding response around the world has been the recognition that there will almost certainly not be enough specialists to cope with the increasing demand for genetic services. Therefore, genetic information and advice will of necessity be-

\footnotetext{
From the ${ }^{1}$ The Murdoch Childrens Research Institute and Department of Paediatrics, The University of Melbourne, and Cooperative Research Centre for Discovery of Genes for Common Human Diseases; ${ }^{2}$ Centre for Program Evaluation, Department of Education, Policy and Management, The University of Melbourne; ${ }^{3}$ Margaret Street Clinic, Melbourne; and ${ }^{4}$ Department of History and Philosophy of Science, The University of Melbourne.

Sylvia Metcalfe, PhD, The Murdoch Childrens Research Institute, Education Unit, 10th Floor, Royal Children's Hospital, Flemington Road, Parkville, Victoria 3052, Australia.

Received: October 29, 2001.
}

Accepted: December 10, 2001. come the domain of primary health care providers, primarily general (family) practitioners (GPs). 1,7,9,10 Genetics has never been a major focus in the training of GPs, and studies in countries such as the United States and the United Kingdom have clearly identified a lack of relevant knowledge of genetics and appropriate referral practices in currently practicing primary care providers. ${ }^{11-19}$ Furthermore, several barriers to the increased uptake of genetics in primary care have been recognized. ${ }^{20,21}$ Consequently, there has been a general call for major educational efforts in the area of modern genetic medicine among health professionals, ${ }^{1,9,22-24}$ and the recognition that consumers also have an important role to play in continuing medical education of GPs by providing feedback and helpful information about consumer needs ${ }^{25-27}$ (and unpublished data, Consumer's Health Forum of Australia, 1999).

To develop effective continuing medical educational (CME) strategies intended to impact on clinical practice, information should initially be gathered to assess the needs and attitudes of the target group, followed by evaluation of these educational strategies on practice. In Australia, knowledge of genetics among GPs and their attitudes to both their role in the practice of genetic medicine and to genetic technologies have received minimal attention compared with other countries. A single published report from a study in Western Australia in 1993 noted that most GPs who had been exposed to a community education program about genetics said that they required further professional education. ${ }^{28}$ Currently, seminar and workshop programs in genetics education are being offered to GPs in various states in Australia ${ }^{29}$ (and personal communications). These are often combined with CME points accredited 
though the Royal Australian College of General Practitioners (RACGP) and include evaluation of the program and content, but there have been no published reports yet on evaluation of practice outcomes and whether these programs meet the needs of GPs.

The present study was undertaken in collaboration with the Victorian Faculty of the RACGP and was designed to research attitudes to genetics and genetic technologies among GPs in Victoria, Australia. The study also aimed to collect information regarding GPs' experiences in dealing with genetics in their practices and their needs with regard to genetics education. GPs' responses were further contextualized by canvassing views from genetics experts, GP educators, and consumer representatives. This strategy would assist with both the development of appropriate education programs and the creation of relevant resources that meet the needs of primary health care practitioners in Australia.

\section{MATERIALS AND METHODS}

Multiple methods, including focus groups, a survey, semistructured interviews, and group consultation with consumer representatives, were used and allowed triangulation of the data. This study was approved by the Human Ethics Research Committee of the Royal Children's Hospital, Melbourne, and fully informed consent was obtained from all participants.

\section{Focus groups}

\section{Recruitment}

Five groups were chosen purposively, ${ }^{30}$ to identify trends across groups. ${ }^{31,32}$ These groups comprised metropolitan GPs $(n=2)$, rural GPs $(n=2$, one by means of teleconferencing), and GP/lecturer-academics $(n=1)$; a sixth group was also chosen to include clinical geneticists and genetic counselors from the Victorian Clinical Genetics Services (VCGS; now known as Genetic Health Services Victoria), a statewide service. The metropolitan GP and one of the rural GP groups were recruited in response to a letter of invitation from the RACGP; these GPs had either attended a CME event organized by the RACGP in the previous 2 years or had referred a patient to the VCGS. The other rural GP focus group was recruited by one of the Divisions of General Practice (Otway Division). These four GP focus groups were offered remuneration, as part of the recruitment process, for their time spent in attending the sessions. The GP lecturers were recruited through their academic interest in general practice.

\section{Question route}

Major areas covered within focus groups included recent experiences managing conditions with a genetic cause or component, the management of pregnancy and possible birth defects, experiences regarding genetic testing and referral to support groups, GPs' level of knowledge about genetics, specific areas in genetics that need to be strengthened in GP education, how genetics education should be organized and delivered, and resources that would be useful to a GP when dealing with a patient that has a genetic condition.

The interviews started with a "round-robin" open question, "When I say the words 'GP Education and Genetics' what is the first thing that comes into your mind?" followed by a few transition questions about the recent experience of GPs, and ending with key focus questions about future genetics education strategies and resource development. Each audiotaped focus group session took approximately 1.5 hours, and groups were run by a moderator and an assistant who took notes.

\section{Individual interviews}

Individual semistructured interviews were held with two leading GP educators to ascertain their current views on genetics education for GPs. Notes were taken during the interview sessions.

\section{Survey of GPs}

GPs who were sent a letter to participate in focus groups also received a survey from the RACGP (Victorian Faculty), as did additional GPs who had previously responded to other RACGP surveys. A total of 875 GPs were sent this survey, the aim of which was to collect information about current experience with patients with genetic conditions, and information about genetics education programs, particularly regarding which topics and types of resources might be of value.

\section{Survey of divisions of general practice}

A questionnaire was sent to the 32 Victorian Divisions of General Practice to collect information about recent educational events that may have included genetics. A follow-up reminder letter was also sent 2 months after the initial letter to prompt returns.

\section{Consumer consultation}

A consumer group consultation was held with members of an umbrella organization of genetic support groups (Genetic Support Network of Victoria). Participants were asked questions on what they perceived to be unique to the role of the GP in managing patients and families with genetic conditions and what GPs' strengths and weaknesses are in this area. The consultation concluded with participants taking part in a nominal group technique exercise, in which a structured brainstorming session aimed to reach consensus. ${ }^{33}$ The consensus was to help establish priorities for genetics educational activities for GPs from the point of view of the consumer. Each participant was asked to respond to the question:

What could GPs be informed about that would improve their management of patients with genetic conditions?

Limited discussion led to a final number of items, which were then ranked in importance from 1 to 3 by each partici- 
pant. The most important items were then determined by a vote.

\section{Analysis of the data}

After the interviews had been carried out, tapes were transcribed and consolidated with the written notes. Transcripts and notes were then coded. All major themes from each interview were displayed on a simple matrix of the type suggested by Miles and Huberman. ${ }^{34}$ Descriptive statistics were calculated for survey results.

\section{RESULTS}

\section{GP response rates and demographics}

A total of 39 GPs took part in the five focus group interviews, held between November of 1999 and February of 2000, with roughly equal numbers of males and females. GPs belonged to solo and large group practices/clinics with a wide-variety of interests and specialties. In general, GPs who participated in the focus groups were very experienced, with over $75 \%$ of participants having worked in general practice for more than 15 years.

Surveys were received from $160 \mathrm{GPs}$, a response rate of $18.3 \%$. Of these, 110 were male and 49 were female, and approximately $85 \%$ had worked in general practice for over 15 years.

\section{Focus groups, interviews, and surveys}

Several themes emerged from the analysis of the coded transcripts of GP and genetics experts focus groups, and interviews with the GP educators.

\section{Recent experience in managing patients with a genetic condition}

All focus groups reported that they had some recent, if sporadic, experience in managing patients with conditions that had a significant genetic cause or component, especially genetic issues relating to pregnancy, such as screening for Down syndrome. Other diseases frequently mentioned were hemochromatosis, Huntington disease, and familial cancers, as well as a few other conditions. However, the groups emphasized that such management was an infrequent part of daily practice. Indeed, $60 \%$ of GPs surveyed also indicated there was only slight demand in their own practice for information about genetic conditions, and $28 \%$ of GPs indicated moderate demand.

GPs in several of the groups said that they would only raise the issue of genetic conditions, birth defects, and/or testing in certain cases (advanced maternal age, family history, ethnic group, consanguineous marriage). As one participant explained:

To sit down and talk with someone about genetic disease when there is no bigger risk than average is not a thing that GPs would do routinely.
Frequently, the management process was patient-driven, and GPs expressed concern that patients often knew more about potential or actual genetic conditions. For example, one GP said:

The parents come in and I feel a little in the dark about it because I have actually been given no information. They've searched the Net and seen all the specialists so I feel a bit like a fish out of water there.

Each of the groups mentioned that they relied on specialists for information and advice and referred patients either to obstetricians, gynecologists, or a genetics clinic. All groups commented that a significant component of their role involved counseling, particularly in explaining the need for tests, support while waiting for the results of tests, explaining the test result, and counseling with regard to other family members. Moreover, all groups expressed concern about dealing with patient fear, anxiety, and trauma. They spoke of the difficulties in explaining genetics in lay terms and of conveying risk and the nondefinitive nature of screening test results, especially prenatal screening. The definition of genetic tests were problematic in that GPs were unsure of what constituted a genetic test, often considering testing only in terms of DNA:

I've ordered things like thalassaemia but I've never ordered a genetic test.

Also, very few GPs said they had had any experience ordering genetic tests, with only three GPs providing an example of specific tests that they had requested. This finding was also reflected in the survey where $62 \%$ stated that they had never, or hardly ever, ordered a genetic test. GPs were skeptical about the relevance of testing when results were unlikely to alter their management of conditions such as diabetes or breast cancer. Overall, the majority of GPs said they would refer patients to specialists for testing.

Although the majority of survey respondents said they had referred patients to a genetics clinic at some time in their career (many from this group were recruited because of prior referrals to a genetics clinic), GPs in the focus groups had more limited experiences with referrals, which was reflected in a comment from one of the genetics experts:

They (GPs) don't refer patients because they have no idea whom to refer them to or any idea that we even see patients.

Many of the genetics experts preferred that GPs only carry out preliminary tests and were concerned that GPs' lack of knowledge and tendency not to refer could, in some cases, be to the detriment of the patient.

Furthermore, four of the five GP groups said they had little or no experience in referring patients to support groups yet, paradoxically, expressed a belief that such groups were beneficial for those patients who sought them out. This finding was also reflected in the survey with $80 \%$ of respondents saying they had never, or hardly ever, referred patients to support groups. GPs said that, in their experience, patients found such 
groups before seeing their GP and often knew more about them than the GPs themselves.

In general, GPs had strong views about their ability to manage a patient with a genetic condition, citing principally that they do not consider genetics to be relevant to their practice. When asked to summarize what they saw as the most important genetics issues for GPs in their day-to-day practice, they raised issues such as the necessity to focus on the most common diseases, the need to do a family tree, and the ability to manage patient stress and anxiety. Indeed, the necessity to improve GPs' counseling skills was an issue raised repeatedly by all the groups.

\section{Genetics knowledge}

Problems relating to GPs' genetics knowledge, education, or both, were a recurring theme throughout the focus groups. Often, GPs admitted that their knowledge of genetics was extremely poor. Many GPs agreed that their level of knowledge depended on when they graduated and what they had learned at medical school. They described their genetics knowledge as "limited," "poor," "basically undergraduate," and "needed updating." As one GP elaborated:

I've been in general practice for 20 years and I think it was only last year that I went to an evening talk with a geneticist, and it was something I hadn't really thought of in 19 years.

The genetic experts also expressed concern about GPs' lack of genetics knowledge. They believed that what GPs did know was, at best, very basic and that GPs were often reluctant to learn more. For instance, one expert believed that GPs just have to hear the word "genetics" and "it is immediately too difficult and too rare." The GP educators also believed that GPs' knowledge of genetics was limited and observed that it was difficult for GPs to keep up-to-date with all the latest developments. They acknowledged that GPs learn in relation to what they encounter in their day-to-day practice. As one GP educator put it:

Learning in general practice is by experience, so this determines how much they know. GPs' knowledge is very contextualised.

An underlying issue for GPs was uncertainty about what they believed constituted a genetic disease and, in particular, whether it meant only single-gene disorders or also those that are multifactorial. For instance, one GP asked:

Are you talking about things that are Mendelian inherited? Are we talking about classic diseases? Because we can talk about heart disease or a family history of asthma. Those conditions do have a genetic component.

The GPs' perceived need to learn about genetics was influenced by their perception of genetic diseases as either rare or common and the probability about whether they would en- counter genetic conditions routinely in their day-to-day practice:

I think we are thinking it (genetics) is only the rare diseases we learned at medical school.

Many GPs believed that they did not know very much about the rare genetic conditions but learned about them "on-thejob" as they arose. However, several GPs believed that, when they do encounter such patients, they are able to manage them well enough.

Another area of deficiency identified by GPs was in their understanding of test results, although even the genetics experts noted that geneticists themselves often found the test reports difficult to understand. As one GP observed:

If it wasn't for the interpretation I got, then I wouldn't have had any idea as to what it all meant. That reflects my ignorance.

Many of the GPs did express a desire to know more about genetics: some believed they would like to know more theory for their own benefit, but most said that the practical relevance of managing patients was paramount in directing their views on which areas needed strengthening. Once again, counseling and communication skills were emphasized. There were several particular genetic conditions that GPs said they wanted to know more about, and these requests were similar to those made in the survey (Table 1). In the area of genetic testing, GPs said they wanted to know more about prenatal testing, cascade testing, when to refer patients for testing, what tests are available, how to order tests, the accuracy of tests, and the future of genetic testing.

\section{Genetics education programs}

Each group was asked to consider strategies to improve GPs' knowledge about genetics and was asked to say how they would organize a genetics education program for GPs. In their responses there was a clear desire that any program should be short and interesting (suggestions ranged from a 3-hour ses-

Table 1

Genetic topics and conditions about which GPs wanted to know more

Topic
Prenatal testing
Counseling
Drawing pedigrees
Condition
Familial cancers
Cystic fibrosis
Fragile X syndrome
Alzheimer disease/dementias
Hemochromatosis
Thalassemias
Huntington disease


sion to a weekend course). Rural GPs emphasized the need to ensure that their colleagues in more remote locations have access to education sessions; not surprisingly, distance education was favored by rural GPs. One GP suggested a distance package that could include audiotapes, video, a teleconference and a reading guide, and others suggested video conferencing from a central point. Both GPs and GP educators suggested using the Divisions of General Practice to help deliver a program on genetics to GPs. GPs also believed that free courses and those that attracted CME points were more likely to get better attendance. Most GPs and the GP educators favored a case-based, practice-relevant approach to the content, with emphasis on keeping the message simple:

An evening seminar talking about 4 to 5 different cases and then you can look at the issues around it as well as some of the facts. I glaze over at lots of information and numbers but I am quite interested in people. That's why I am a GP.

To view cases from different perspectives, the GP educators suggested that sessions might be organized with three or four members of a team (e.g., GPs and specialists) and should integrate teaching of genetics with other topics such as hypertension, in ways that emphasize the importance of genetics, and also to place it into a practical context of patient management.

GPs were asked to nominate various resources and materials that should be produced to help GPs learn effectively about genetics. Categories of materials included electronic (CD$\mathrm{ROM}$, the Internet) and printed material (mainly in updatable folder format), with other suggestions such as a "hot-line" (telephone advisory service), audiotape for the car, and inclusion of information in the clinical notes "Medical Director" software package commonly used by GPs. In particular, GPs asked for such resources to include referral details and information for patients, and stressed that all information should be presented simply. Results from the survey revealed how GPs rated the usefulness of different modes of delivering genetics education and these are shown in Figure 1.

\section{Survey of divisions of general practice}

A total of 20 replies were received from the 32 Divisions of General Practice sent a questionnaire. Only five Divisions had offered or developed an activity involving genetics for GPs, one of which had been canceled (in a nonmetropolitan region) because of lack of interest. However, more than half of the Divisions that responded were prepared to assist in piloting educational activities/resources about genetics.

\section{Consumer consultation}

The group consultation was held with 16 members of the Genetic Support Network of Victoria (GSNV), representing 13 different support groups. There was a wide range of comments about what GPs do and do not do well in managing patients with a genetic condition. However, they suggested that younger GPs are more likely than older GPs to have a positive

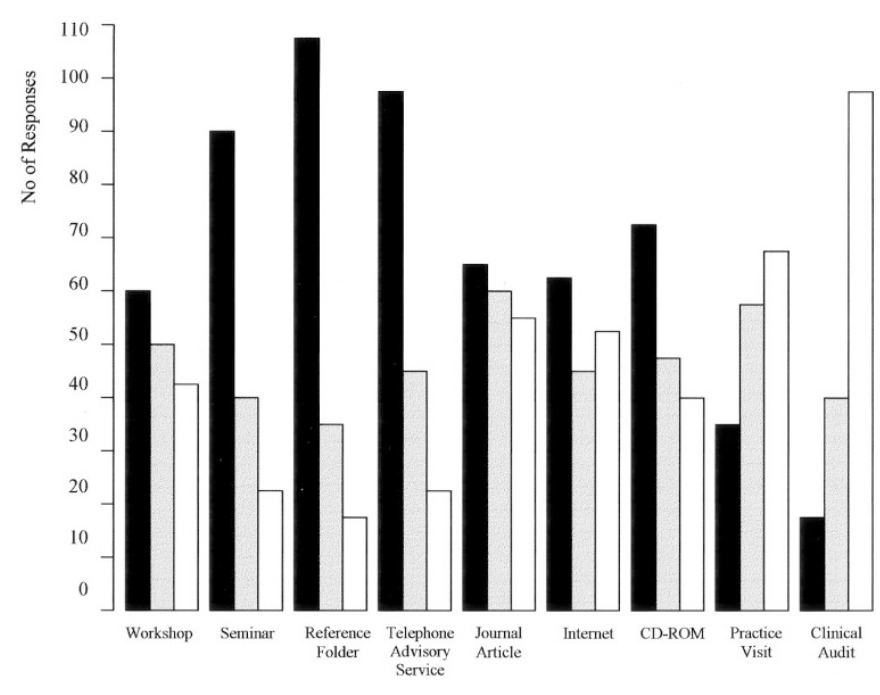

Fig. 1 Usefulness of delivering different modes of education. GPs in the survey were asked to rate, on a scale of 1 to 5 , which mode of delivery they thought would be (1) not at all useful, (3) useful, (5) very useful, or somewhere between these options. A reference folder as a resource is likely to contain relevant information about particular genetic conditions, including which patients might be at risk, which investigations to carry out, management issues, implications for the family, referral to genetic services and support groups; in addition, there might be patient information sheets and basic information about genetics, genetic testing, and pedigree drawing. Black bars, very useful; shaded bars, moderately useful; white bars, not at all useful.

and helpful attitude toward patients with a genetic condition. From the nominal group discussion, the most important aspects that the group thought a GP could be informed about that would improve their management of patients with a genetic condition were as follows:

- To know where to find information

- To trust a patient's/parents' judgment

- To have good communication skills

- To understand that simple symptoms may be more serious and they need to be extravigilant

- To meet and talk to consumers

- To treat families not just the individual

- To support family decisions

- That managing a patient with a genetic condition requires a long-term plan

\section{CONCLUSION}

Many of the findings from this study indicate that the experience of Australian GPs, in dealing with genetics issues in their practice, is similar to that of family practitioners in the United States and Europe. Australian GPs reported relatively low use of genetic services, which reflects the picture with primary care physicians in Canada ${ }^{18}$ and the United States. ${ }^{15,35}$ They also identified that, like their counterparts in the United States, the referral and management process was often patient-driven. ${ }^{17}$ Furthermore, GPs in this study responded in a manner similar to family physicians in the United Kingdom and United States, who perceived that genetics was not very relevant to their cur- 
rent practice but would become more important in the future. ${ }^{20,36,37}$ Although specific details of genetics knowledge were not assessed, most GPs in this study perceived their level of knowledge to be extremely poor. This is in contrast to some studies elsewhere in which many doctors perceived their knowledge to be adequate, despite assessment of their knowledge indicating to the contrary. ${ }^{18} \mathrm{~A}$ recurring theme emerging from this study was GPs' concerns to improve their counseling skills, an area that they believed should be emphasized in any educational program aimed at family practitioners, and a point that was echoed in the consumer consultation.

In discussing genetics educational strategies, there were many views on the best methods of delivery and resources, with a reference folder, seminars, and a "hot-line" being the most popular. Interestingly, practice visits and clinical audits were the least preferred, although there is evidence to suggest that these practice-based interventions provide the most effective means of improving the performance of the health practitioner and, sometimes, of health care outcomes. ${ }^{38-41}$ Clearly, it is important that such practice-based interventions be delivered in a nonthreatening way to overcome GPs' perceptions of their intrusive nature. Education programs should also give special consideration to the needs of rural GPs who, in this study, generally favored distance education and satellite links. GPs also prefer courses that are short, free, and earn CME points.

When considering the design of content for any genetics programs and resources, it is worth noting that all GPs in this study agreed that content should be made relevant to their day-to-day practice, preferably making a difference to their management of patients, and should be presented simply and in an interesting way. Content that focuses on taking a family history and drawing a pedigree, on the more common genetic conditions, genetic testing, counseling skills, and on how and when to refer, was considered most important by GPs. Furthermore, the input of consumers, primarily through genetic support groups, into education programs should be sought, particularly when dealing with issues around counseling and communication.

The findings from this study have the potential to help educators develop appropriate and relevant programs in genetics for GPs in Australia, and, given the obvious overlap of issues with other countries, these programs are likely to be transferable to international settings.

\section{Acknowledgments}

The authors acknowledge the Department of Human Services, Victoria, the University of Melbourne, and the Cooperative Research Center for Discovery of Genes for Common Human Diseases for funding support. The CRC for the Discovery of Genes for Common Human Diseases is established and supported by the Australian Government's Cooperative Research Centers' Program. The assistance of Dr. Anna Henry in data analysis and Mr. Martin Sweeney (Victorian Faculty,
Royal Australian College of General Practitioners) for recruitment and coordination of the study are also gratefully acknowledged.

\section{References}

1. Collins F. Preparing health professionals for the genetic revolution. JAMA 1997;278: 1285-1286.

2. Bell J. The new genetics: the new genetics in clinical practice. BMJ 1998;316:618620.

3. Collins F. Genetics: an explosion of knowledge is transforming clinical practice. Geriatrics 1999;54:41-47.

4. Collins F, Bochm K. Avoiding casualties in the genetic revolution: the urgent need to educate physicians about genetics. Acad Med 1999;74:48-49.

5. Harris R, Reid M. Medical genetic services in 31 countries: an overview. Eur J Hum Genet 1997;5(suppl 2):3-21.

6. Holtzman N, Shapiro D. Genetic testing and public policy. BMJ 1998;316:852-856.

7. Kinmoth A, Reinhard J, Bobrow M, Pauker S. Implications for clinical services in Britain and the United States. BMJ 1998;316:767-770.

8. Department of Human Services. Genetics services in Victoria: a discussion paper. Melbourne Public Health Division, Victorian Government Department of Human Services, 1997.

9. Stephenson J. As discoveries unfold, a new urgency to bring genetic literacy to physicians. JAMA 1997;278:1225-1226.

10. Emery J, Watson E, Rose P, Andermann A. A systematic review of the literature exploring the role of primary care in genetics service. Fam Pract 1999;16:426-445.

11. Firth H, Lindenbaum R. UK clinicians' knowledge of and attitudes to the prenatal diagnosis of single gene disorders. J Med Genet 1992;29:20-23.

12. Hofman K, Tambor E, Chase G, Geller G, Faden R, Holtzman N. Physicians' knowledge of genetics and genetic tests. Acad Med 1993;68:625-632.

13. Kershner M, Hammond E, Donnenfield A. Knowledge of genetics among residents in obstetrics and gynecology. Am J Hum Genet 1993;53:1356-1358.

14. Boulton M, Williamson R. General practice and new genetics: what do general practitioners know about community carrier screening for cystic fibrosis? Public Understand Sci 1995;4:255-267.

15. Friedman L, Plon S, Cooper P, Weinberg A. Cancer genetics survey of primary care physicians' attitudes and practices. J Cancer Educ 1997;12:199-203.

16. Sadler M. Serum screening for Down's syndrome: how much do health professionals know? Br J Obstet Gynaecol 1997;104:176-179.

17. Hayflick S, Eiff P, Carpenter L, Steinberger J. Primary care physicians' utilization and perceptions of genetic services. Genet Med 1998;1:13-21.

18. Hunter A, Wright P, Cappelli M, Kasaboski A, Surh L. Physician knowledge and attitudes towards molecular genetic (DNA) testing of their patients. Clin Genet 1998;53:447-455.

19. Fry A, Campbell H, Gudmunsdottir H, Rush R, Porteous M, Gorman D, Cull A. GPs' views on their role in cancer genetics services and current practice. Fam Pract 1999;16:468-474.

20. Watson E, Shickle D, Qureshi N, Emery J, Austoker J. The "new genetics" and primary care: GPs' views on their role and their educational needs. Fam Pract 1999; 16:420-425.

21. Mountcastle-Shah E, Holtzman NA. Primary care physicians' perceptions of barriers to genetic testing and their willingness to participate in research. Am J Med Genet 2000;94:409-416.

22. Stephenson J. Group drafts core curriculum for "What docs need to know about genetics." JAMA 1998;279:735-736.

23. Clearihan L. The third revolution. Aust Fam Physician 1998;27:1079.

24. Emery J, Hayflick S. The challenge of integrating genetic medicine into primary care. BMJ 2001;322:1027-1030.

25. RCGP Report. Genetics in primary care. A Report from the Faculty Genetics Group, Occasional Paper 77: Royal College of General Practitioners, 1998.

26. Hays R, Bunt J, Smith D, O'Connor T. Should consumers be involved with CME? Aust Fam Physician 1998;27:778.

27. Darr A. The patient's perspective. In: Rose P, Lucassen A, editors. Practical genetics for primary care. Cambridge: Oxford University Press, 1999:331-338.

28. Walpole I, Watson C, Moore D, Goldblatt J, Bower C. Evaluation of a project to enhance knowledge of hereditary diseases and management. J Med Genet 1997;34: $831-837$.

29. Summers K, MacMillan J. Genetic education for populace and proliferation. Paper presented at the Hum Genet Society of Australasia, 24th Annual Scientific Meeting, Sydney, 1999.

30. Patton MQ. Qualitative evaluation and research methods, 2nd ed. Newbury Park: Sage, 1990.

31. Krueger R. Focus groups, 2nd ed. California: Sage, 1994. 
32. Krueger R, Morgan D. The focus group kit. California: Sage, 1998

33. Moore CM. Group techniques for idea building, 2nd ed. California: Sage, 1994.

34. Miles M, Huberman AM. Qualitative data analysis, 2nd ed. California: Sage, 1994.

35. Kolb S, Aguilar M, Dinenberg M, Kaye C. Genetics education for primary care providers in community health settings. J Community Health 1999;24:45-59.

36. Fetters M, Doukas D, Phan K. Family physicians' perspectives on genetics and the human genome project. Clin Genet 1999;56:28-34.

37. Kumar S, Gantley M. Tensions between policy makers and general practitioners in implementing new genetics: grounded theory interview study. BMJ 1999;319:14101413.
38. Davis D, Thomson M, Oxman A, Haynes B. Evidence for the effectiveness of CME: a review of 50 randomized controlled trials. JAMA 1992;268:1111-1117.

39. Davis D, Thomson M, Oxman A, Haynes B. Changing physician performance: a systematic review of the effect of continuing medical education strategies. JAMA 1995;274:700-705.

40. Collins S. CME: what works? Aust Fam Physician 1996;25:278-280.

41. Davis D, O’Brien MA, Freemantle N, Wolf F, Mazmanian P, Taylor-Vaisey A. Impact of formal continuing medical education: do conferences, workshops, rounds, and other traditional continuing education activities change physician behavior or health care outcomes? JAMA 1999;282:867-874 